\title{
Transcranial direct current stimulation improves the QT variability index and autonomic cardiac control in healthy subjects older than 60 years
}

This article was published in the following Dove Press journal:

Clinical Interventions in Aging

16 November 2016

Number of times this article has been viewed

\author{
Gianfranco Piccirillo' \\ Cristina Ottaviani ${ }^{2}$ \\ Claudia Fioruccil \\ Nicola Petrocchi \\ Federica Moscucci' \\ Claudia Di lorio' \\ Fabiola Mastropietri' \\ Ilaria Parrotta' \\ Matteo Pascucci' \\ Damiano Magrì ${ }^{3}$ \\ 'Department of Cardiovascular, \\ Respiratory, Nephrological, \\ Anestesiological and Geriatric \\ Sciences, "Sapienza" University, \\ ${ }^{2}$ Neuroimaging Laboratory, IRCCS \\ Santa Lucia Foundation, ${ }^{3}$ Department \\ of Clinical and Molecular Medicine, \\ University of Rome "Sapienza", \\ Rome, Italy
}

Background: Noninvasive brain stimulation technique is an interesting tool to investigate the causal relation between cortical functioning and autonomic nervous system (ANS) responses. Objective: The objective of this report is to evaluate whether anodal transcranial direct current stimulation (tDCS) over the temporal cortex influences short-period temporal ventricular repolarization dispersion and cardiovascular ANS control in elderly subjects.

Subjects and methods: In 50 healthy subjects (29 subjects younger than 60 years and 21 subjects older than 60 years) matched for gender, short-period RR and systolic blood pressure spectral variability, QT variability index (QTVI), and noninvasive hemodynamic data were obtained during anodal tDCS or sham stimulation.

Results: In the older group, the QTVI, low-frequency (LF) power expressed in normalized units, the ratio between LF and high-frequency (HF) power, and systemic peripheral resistances decreased, whereas HF power expressed in normalized units and $\alpha$ HF power increased during the active compared to the sham condition $(P<0.05)$.

Conclusion: In healthy subjects older than 60 years, tDCS elicits cardiovascular and autonomic changes. Particularly, it improves temporal ventricular repolarization dispersion, reduces sinus sympathetic activity and systemic peripheral resistance, and increases vagal sinus activity and baroreflex sensitivity.

Keywords: transcranial direct current stimulation, QT variability, heart rate variability, autonomic nervous system, aging

\section{Introduction}

Aging is an important risk factor for coronary disease, heart failure, and sudden cardiac death. According to the classic multifactorial theory proposed by Zipes and Wellens, ${ }^{1}$ aging brings about a sudden increase in sympathetic activity along with diminished vagal nerve activity. Both changes act singly or in concert as transient events triggering malignant ventricular arrhythmias. For this reason, sudden and unexpected events with high emotional content, such as earthquakes, terrorist attacks, sexual activities, or anger, can lead to sudden cardiac death, especially in older subjects or patients with structural heart disease..$^{2-4}$

In the last decade, many observations suggested that the insular cortex (IC) has a central role in favoring sudden cardiac death. The right insula is considered as the site where both sympathetic hyperactivity and left ventricular repolarization dispersion originate during acute stroke or transient ischemic attacks. ${ }^{5-8}$ Other studies indicated that the left IC intervenes in baroreflex and parasympathetic control. ${ }^{6,7,9,10}$
Correspondence: Gianfranco Piccirillo Department of Cardiovascular, Respiratory, Nephrological, Anesthesiological and Geriatric Sciences, "Sapienza" University of Rome, 00185 Rome, Italy Tel +39064667 0118

Email gianfranco.piccirillo@uniromal.it 
Recently, it has been suggested that transcranial direct current stimulation (tDCS) over the temporal cortex (TC) can reach subcortical areas, such as the IC located just below the TC. ${ }^{11,12}$ tDCS modulates spontaneous neuronal network activity through the application of weak electrical currents to different cortical areas. At the neuronal level, the primary mechanism of action is the induction of polaritydependent changes in cortical excitability. ${ }^{13}$ Unfortunately, most of the existing studies have been designed with the aim to understand the safety of noninvasive brain stimulation using cardiovascular parameters and not to study the brain-heart relationship.

The TC and IC have been associated with autonomic nervous system (ANS) control and the awareness of emotional feelings from the body, ${ }^{11}$ and it has been demonstrated that tDCS, applied over T3 targeting the left IC, increases the parasympathetic modulation in athletes at rest. Results have been replicated further showing that such effects remain during light and moderate exercise also, as indexed by the delayed vagal withdrawal. ${ }^{12}$ The authors conclude that besides the direct effects of anodal tDCS on the TC, this stimulation might also have reached subcortical areas, such as the IC.

Despite these promising results, up to now no studies have investigated tDCS-induced changes in parasympathetic sinus and cardiac function, sympathetic cardiovascular activity, and temporal ventricular repolarization. To overcome this limitation, we tested whether tDCS could increase parasympathetic sinus and cardiac function, reduce sympathetic cardiovascular activity, and improve temporal ventricular repolarization dispersion in healthy older subjects who particularly have an ANS control characterized by low baroreflex sensitivity, ${ }^{14,15}$ decreased heart rate variability, ${ }^{15-21}$ and increased myocardial temporal dispersion. ${ }^{22}$ Power spectral analysis of short-period RR, systolic blood pressure (SBP), and QT interval variability was used to evaluate ANS activity and temporal repolarization dispersion. ${ }^{22-27}$

\section{Subjects and methods}

\section{Participants}

The final sample was composed of 29 participants younger than 60 years ( 17 women and 12 men; mean age $=35.97$ [10.9]; range $23-57$ years) and 21 participants aged 60 years or older ( 10 women and 11 men; mean age $=69.67$ [6.25] years). Only one participant was non-Caucasian. Ten subjects had to be excluded from the analyses because of missing data or excessive artifacts. Patients were recruited from public advertisement and from staff and students of Policlinico Umberto I. Patients younger than 18 years, history of head injury, major medical neurological or psychiatric disorder, cognitive impairment, history of substance or alcohol abuse or dependence, diagnosis of heart disease, obesity (body mass index $>30 \mathrm{~kg} / \mathrm{m}^{2}$ ), and pregnancy were excluded. Finally, sedentary subjects with low coronary risk factors were selected. All the participants were medication-free and provided written informed consent. Written informed consent was obtained for publication of the associated image. The bioethical committee of S Lucia Foundation, Rome, Italy, approved the study. Participants were compensated for their time.

\section{Procedure}

A randomized, sham-controlled, within-subjects design was used. Subjects were randomized in a counterbalanced order to receive both $\mathrm{tDCS}$ stimulation conditions. Data were assessed in 2 nonconsecutive days. All sessions occurred between $12 \mathrm{pm}$ and $4 \mathrm{pm}$. Subjects were asked to avoid drinking coffee and smoking cigarettes 24 hours prior to the sessions. The experimental protocol was completed within a week.

\section{tDCS}

An anodal or a sham tDCS was applied in a counterbalanced random order over T3 (2 mA during 15 minutes) using the brain STIM device (E.M.S. srl, Bologna, Italy; Figure 1). A cathodal tDCS condition was not included because it is well proven that anodal tDCS increases cortical excitability, whereas the effects of cathodal tDCS are still a matter of debate. ${ }^{28}$ The electric current was applied using a pair of sponges soaked in saline solution $(140 \mathrm{mM}$ of $\mathrm{NaCl}$ dissolved in Milli-Q water) involving both electrodes $\left(35 \mathrm{~cm}^{2}\right) .{ }^{29}$ The electrodes (anodal and cathodal) were connected to a constant current stimulation device with three power batteries.

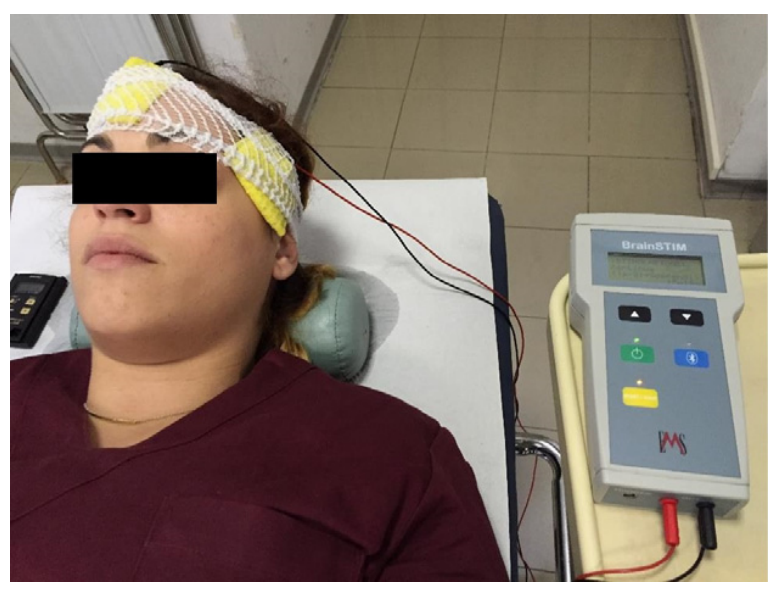

Figure I Photograph taken during T3 anodal transcranial direct current stimulation (tDCS) in a representative subject.

Note: Photograph by the author. 

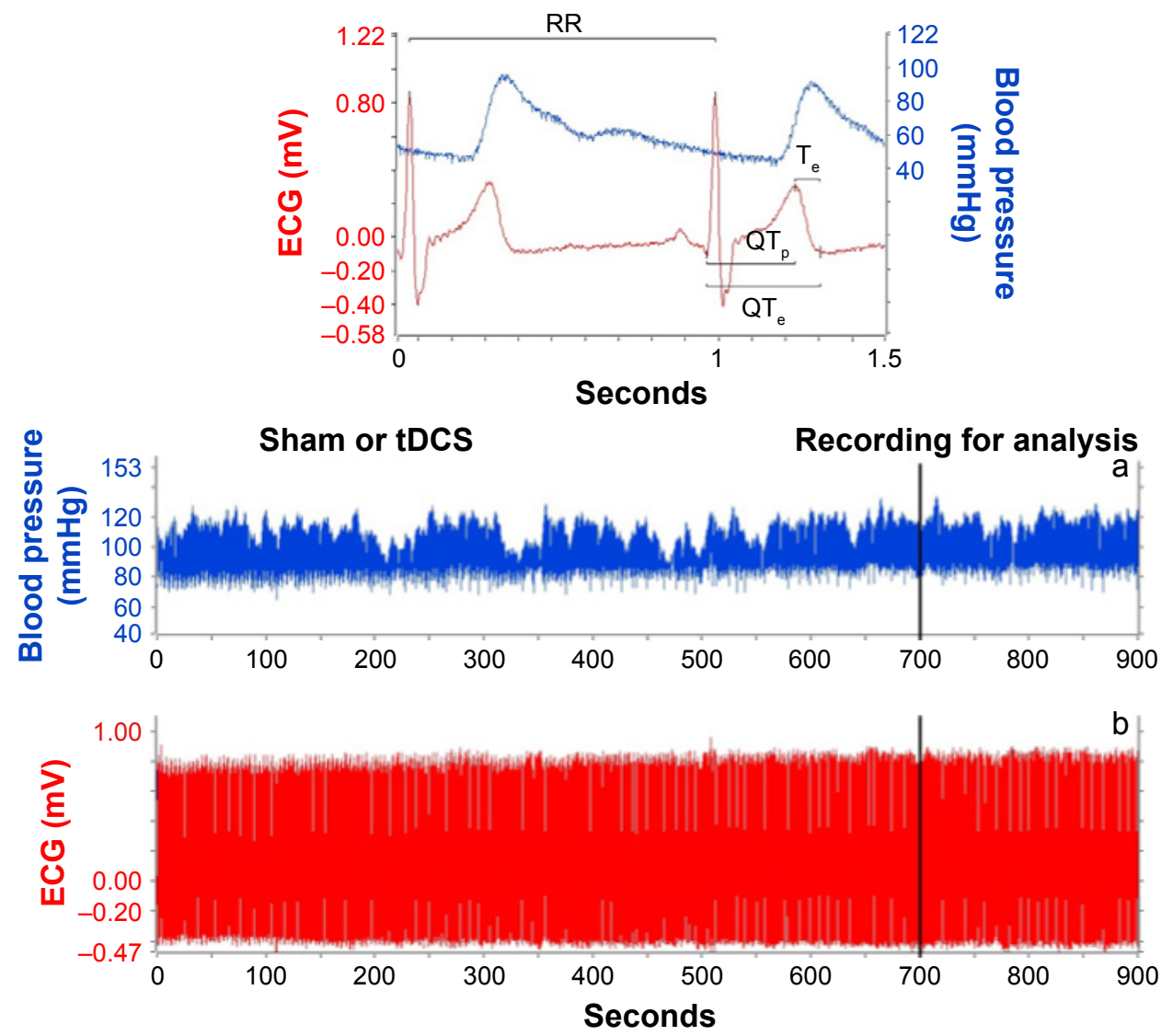

Figure 2 An example of a I5-minute recording during sham or real anodal transcranial direct current stimulation (tDCS).

Notes: (a) shows in detail the examined electrocardiogram (ECG) and blood pressure variables (b). The following intervals were measured: RR, $Q T$ (from the $\mathrm{Q}$ wave to the $\mathrm{T}$ wave end), $\mathrm{QT}$ ( from the $\mathrm{Q}$ wave to the $\mathrm{T}$ wave peak), and $\mathrm{T}_{\mathrm{e}}$ (difference between $\mathrm{QT}$ and $\mathrm{QT} \mathrm{T}_{\mathrm{p}}$ ).

The breathing cycle was controlled (15 breaths/min; $0.25 \mathrm{~Hz}$ ) throughout the testing sessions. ${ }^{30}$ The continuous electrocardiogram (ECG) and beat-to-beat blood pressure recordings were made along the experiment; however, only the last 5 minutes of each registration (anodal and sham) was used for the analyses (Figure 2).

For the anodic stimulation targeting left IC, the anode was placed over T3 area according to the international EEG 10-20 system. The cathode was placed over the supraorbital contralateral area (Fp2) and fixed by elastic bands. The electrodes were placed in the same position of the anodal stimulation to perform the sham condition. However, the stimulator was turned off after 30 seconds. ${ }^{31}$ When sham began participants felt a tingling or an itching sensation identical to the tDCS but received no further current. This procedure allowed participants to remain "blind" to the stimulation polarity received during the test and ensured a sham control effect. ${ }^{32}$

\section{Physiological data processing}

ECG and beat-to-beat blood pressure (Finometer ${ }^{\mathrm{TM}}$; FMS, Arnhem, the Netherlands) signals were acquired and digitalized with a custom-designed card (National Instruments USB-6008; National Instruments, Austin, TX, USA) at a sampling frequency of $500 \mathrm{~Hz}$. Points used for the ECG segment analysis were detected automatically by a classic adaptive derivative/threshold algorithm. Software for data acquisition, storage, and analysis was designed and produced by our research group with the LabView program (National Instruments). After a linear interpolation, an expert cardiologist (GP) checked the different points and, when needed, manually corrected the mistakes with an interactive software. ${ }^{14-17,33}$ All ECG and blood pressure data were analyzed in a single-blind fashion. None of the evaluators knew whether participants received anodal or sham tDCS.

Heart rate, blood pressure, QT variability, and other hemodynamic variables (stroke volume, cardiac output, and peripheral resistances) were obtained from the last 5-minute segments in ECG and beat-to-beat blood pressure recordings. From the same 5-minute ECG segment (Figure 2), the corrected $\mathrm{QT}_{\mathrm{e}}, \mathrm{QT}_{\mathrm{p}}$, and $\mathrm{T}_{\mathrm{e}}$ intervals were obtained according to the formulas proposed by Bazett $\left(\mathrm{QT}_{\mathrm{e}} / \mathrm{RR}^{0.5} ; \mathrm{QT}_{\mathrm{p}} / \mathrm{RR}^{0.5} ; \mathrm{T}_{\mathrm{e}} /\right.$ $\left.\mathrm{RR}^{0.5}\right)$, Friedericia $\left(\mathrm{QT}_{\mathrm{e}} / \mathrm{RR}^{0.33} ; \mathrm{QT}_{\mathrm{p}} / \mathrm{RR}^{0.33} ; \mathrm{T}_{\mathrm{e}} / \mathrm{RR}^{0.33}\right)$, Lilly 
$\left(\mathrm{QT}_{\mathrm{e}} / \mathrm{RR}^{0.4} ; \mathrm{QT}_{\mathrm{p}} / \mathrm{RR}^{0.4} ; \mathrm{T}_{\mathrm{e}} / \mathrm{RR}^{0.4}\right)$, and Framingham $\left(\mathrm{QT}_{\mathrm{e}}+\right.$ $[0.154 \times\{1,000-\mathrm{RR}\}] ; \mathrm{QT}_{\mathrm{p}}+[0.154 \times\{1,000-\mathrm{RR}\}] ; \mathrm{T}_{\mathrm{e}}+$ $[0.154 \times\{1,000-\mathrm{RR}\}]){ }^{26}$

The following intervals from the respective time series in ECG recordings were measured: $\mathrm{RR}, \mathrm{QT}_{\mathrm{e}}$ (from the $\mathrm{Q}$ wave to the $\mathrm{T}$ wave end), $\mathrm{QT}_{\mathrm{p}}$ (from the $\mathrm{Q}$ wave to the $\mathrm{T}$ wave peak), and $\mathrm{T}_{\mathrm{e}}$ (difference between $\mathrm{QT}_{\mathrm{e}}$ and $\mathrm{QT}$ ) (Figure 2). ${ }^{24,26,27}$ Therefore, the mean and variance values for each of these intervals were calculated and then the original formula proposed by Berger et $\mathrm{al}^{34}$ was used to calculate three different QT variability indexes (QTVIs) (Figure 3). ${ }^{24,26,27}$

$$
\begin{gathered}
\mathrm{QT}_{\mathrm{e}} \mathrm{VI}=\log _{10}\left\{\frac{\left[\left[\mathrm{QT}_{\mathrm{e}} \text { variance }\right] /\left[\mathrm{QT}_{\mathrm{e}} \text { mean }\right]^{2}\right]}{\left[[\mathrm{RR} \text { variance }] /[\mathrm{RR} \text { mean }]^{2}\right]}\right\} \\
\mathrm{QT}_{\mathrm{p}} \mathrm{VI}=\log _{10}\left\{\frac{\left[\left[\mathrm{QT}_{\mathrm{p}} \text { variance }\right] /\left[\mathrm{QT} \mathrm{p}_{\mathrm{p}} \text { mean }\right]^{2}\right]}{\left[[\mathrm{RR} \text { variance }] /[\mathrm{RR} \text { mean }]^{2}\right]}\right\} \\
\mathrm{T}_{\mathrm{e}} \mathrm{VI}=\log _{10}\left\{\frac{\left[\left[\mathrm{T}_{\mathrm{e}} \text { variance }\right] /\left[\mathrm{T}_{\mathrm{e}} \text { mean }\right]^{2}\right]}{\left[[\mathrm{RR} \text { variance }] /[\mathrm{RR} \text { mean }]^{2}\right]}\right\}
\end{gathered}
$$

From the same 5-minute ECG and BP segments, the total power of RR intervals and $\mathrm{SBP}\left(\mathrm{TP}_{\mathrm{RR}}\right.$ and $\left.\mathrm{TP}_{\mathrm{SBP}}\right)$ and their total spectral density were also determined. ${ }^{35}$ For RR and SBP, the following spectral components were calculated: a high-frequency $\left(\mathrm{HF}_{\mathrm{RR}}\right.$ and $\mathrm{HF}_{\mathrm{SBP}}$ ) component (from 0.15



Figure 3 Example of a 5-minute ECG recording: $\mathrm{RR}, \mathrm{QT}$ (from the $\mathrm{Q}$ wave to the $\mathrm{T}$ wave end), $\mathrm{QT}$ ( (from the $\mathrm{Q}$ wave to the $\mathrm{T}$ wave peak), and $\mathrm{T}_{\mathrm{e}}$ (difference between $\mathrm{QT}_{\mathrm{e}}$ and $\mathrm{QT}_{\mathrm{p}}$ ) intervals and relative variability indexes: SDNN, $\mathrm{QT} \mathrm{T}_{\mathrm{V}} \mathrm{VI}$, $\mathrm{QT}_{\mathrm{p}} \mathrm{VI}$, and $\mathrm{T}_{\mathrm{e}} \mathrm{VI}$.

Abbreviations: ECG, electrocardiogram; SDNN, standard deviation of all R-R intervals. to $0.40 \mathrm{~Hz}$ ), a low-frequency $\left(\mathrm{LF}_{\mathrm{RR}}\right.$ and $\left.\mathrm{LF}_{\mathrm{SBP}}\right)$ component (from 0.04 to $0.15 \mathrm{~Hz} \mathrm{Eq}$ ), and a very low-frequency $\left(\mathrm{VLF}_{\mathrm{RR}}\right.$ and $\left.\mathrm{VLF}_{\mathrm{SBP}}\right)$ component $(<0.04 \mathrm{~Hz} \mathrm{Eq})$. LF and $\mathrm{HF}$ central frequencies (Figure 4) were also measured. The $\alpha$ index was calculated by dividing the square root of the spectral density for heart rate by the square root of the corresponding spectral density for SPB, as described by Robbe et $\mathrm{al}^{36}$ and later by other investigators: ${ }^{14,33,37,38} \alpha \mathrm{LF}=\sqrt{\mathrm{LF}} \mathrm{RR} / \sqrt{\mathrm{LF}} \mathrm{SBP}$; $\alpha \mathrm{HF}=\sqrt{\mathrm{HF}} \mathrm{RR} / \sqrt{ } \mathrm{HF}$ SBP (Figure 4).

The same ECG intervals, together with beat-to-beat SBP recordings, were also used to analyze power spectra with an autoregressive algorithm also for $\mathrm{QT}_{\mathrm{e}}, \mathrm{QT}_{\mathrm{p}}$, and $\mathrm{T}_{\mathrm{e}}$ intervals. The same order of autoregressive model in sham or during tDCS in the same subject was used, normally the order used by the model was between 10 and 20 (sham or tDCS order: 16 \pm 4 ). Cross-spectral analysis was then used to evaluate the reciprocal influence (coherence function) between RR, QT, $\mathrm{QT}_{\mathrm{p}}$, and $\mathrm{T}_{\mathrm{e}} .^{22,32,39,40}$

Coherence expresses the fraction of power at a given frequency in either time series and provides an index of a linear relationship between the input and output signals. The coherence function $\gamma[f]$ was then computed according to the following formula: ${ }^{22,32,39,40}$

$$
\gamma[f]=\frac{|P \operatorname{xy}[f]|^{2}}{P \operatorname{xx}[f] P \operatorname{yy}[f]}
$$

where $f$ is frequency, $\operatorname{Pxx}[f]$ is the RR interval spectrum, $P y y[f]$ is the QT interval spectrum, and $P x y[f]$ is the cross spectrum. The coherence function measures the degree of linear interaction between RR and QT interval oscillations as a function of their frequency. The value of the coherence function ranges between 0 and 1 . Mean coherences were measured by averaging $\gamma[f]$ over the frequency bands: from 0 to $0.50 \mathrm{~Hz}$.

\section{Statistical analysis}

To better understand the influences of anodal tDCS on the autonomic functioning of elderly people, participants were grouped according to age: $<60$ and $\geq 60$ years. Unless otherwise indicated, all data are expressed as mean \pm standard deviation. Data with skewed distribution are given as median and interquartile range (75th percentile to 25 th percentile). Categorical variables were analyzed with the $\chi^{2}$ test.

One-way analysis of variance was used to compare data for the normally distributed variables between the two groups with different age. On the contrary, Mann-Whitney test was used to compare non-normally distributed variables (as evaluated 


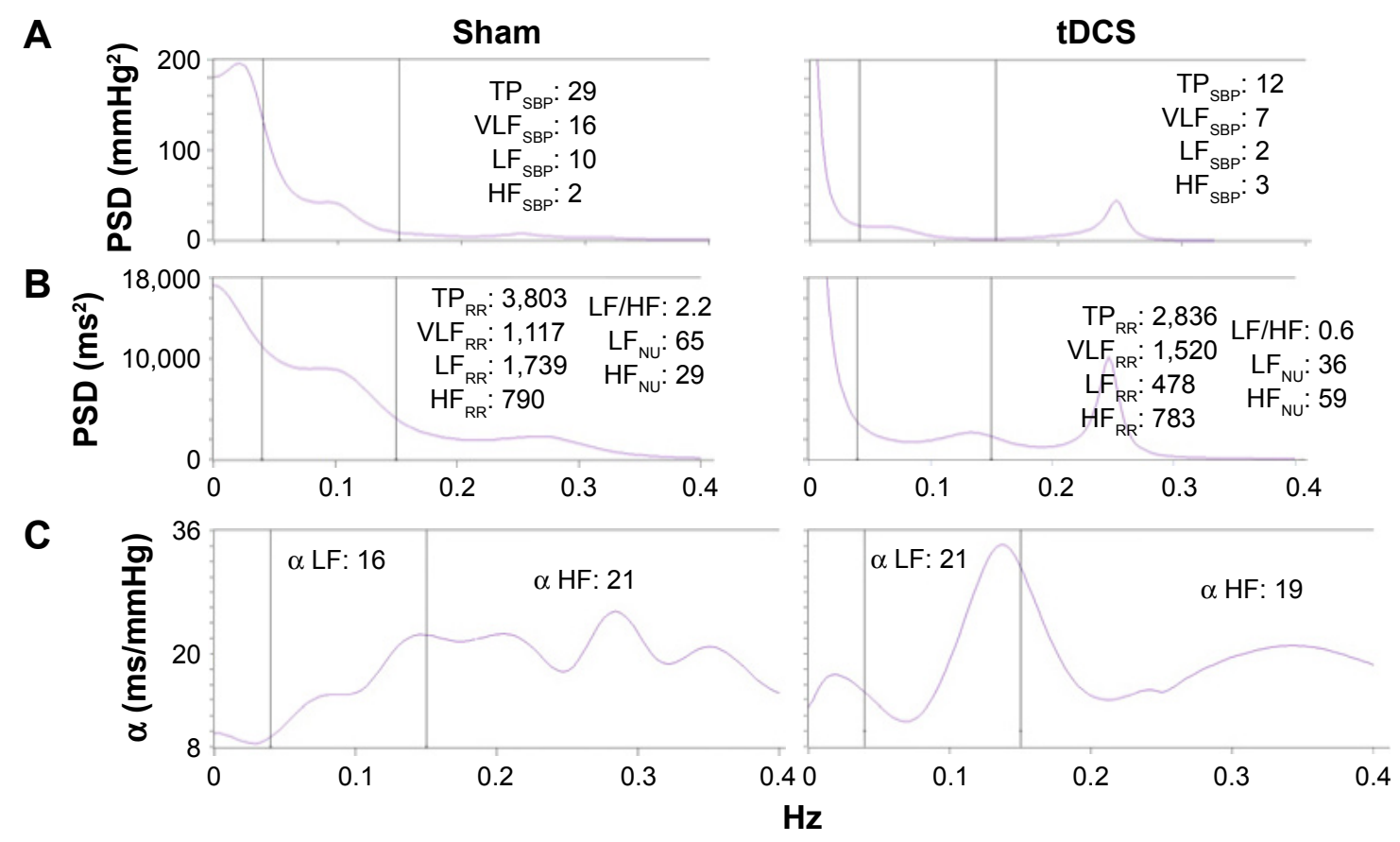

Figure 4 (A) shows the spectrum for SBP, (B) shows the R-R variability spectrum, and (C) shows the index during sham (left panel) or active tDCS (right panel). Notes: Alpha indexes: the relationship between the square root of a single spectral component of R-R variability (LF or HF) and the square root of the same spectral component for SBP. The $(\mathbf{C})$ shows the three spectral windows considered: a LF power $(0.04-0.15 \mathrm{~Hz})$ and a HF power $(0.15-0.40 \mathrm{~Hz})$. R-R and arterial pressure variability were recorded simultaneously during controlled breathing. Note the increased $\mathrm{HF}_{\mathrm{NU}}$ and decreased $\mathrm{LF}_{\mathrm{NU}}$ and LF: $\mathrm{HF}$ during tDCS, a pattern reflecting a sinus vagal increase and sinus sympathetic decrease. LF:HF, ratio between LF and HF. ${ }^{30,35}$

Abbreviations: SBP, systolic blood pressure; tDCS, transcranial direct current stimulation; LF, low frequency; HF, high frequency; TP, total power; VLF, very low-frequency; $\mathrm{NU}$, normalized units; PSD, power spectral density.

by Kolmogorov-Smirnov test) between the two groups with different age. Paired Student's $t$-test or Wilcoxon test was used to evaluate differences in the same group during sham or tDCS for the data with normal or non-normal distribution, respectively. Stepwise multiple regression analysis was used to determine the association between the studied variables and age during sham or tDCS. $P$-values $\leq 0.05$ were considered statistically significant. All data were analyzed with SPSS-PC+ (SPSS-PC+ Inc, Chicago, IL, USA).

\section{Results}

With the exception of age, no other clinical characteristics differed significantly between the two groups (Table 1). The two groups had no differences for number of smokers (three vs two subjects, $P$ : nonsignificant) or physical activity levels.

As shown in Tables 2 and 3 in both experimental conditions, elderly participants has lower RR variance $(P<0.05)$, $\mathrm{TP}_{\mathrm{RR}}(P<0.05), \mathrm{LF}_{\mathrm{RR}}(P<0.05), \alpha \mathrm{LF}(P<0.05)$, stroke volume $(P<0.001)$, cardiac output $(P<0.001)$, and $\mathrm{VLF}_{\mathrm{RR}}$ $(P<0.05)$ and higher QT variance $(P<0.05), \mathrm{QT}_{\mathrm{e}} \mathrm{VI}(P<0.05$; Figure 5), $\mathrm{QT}_{\mathrm{p}} \mathrm{VI}(P<0.05), \mathrm{T}_{\mathrm{e}} \mathrm{VI}(P<0.05)$, peripheral resistances, $\mathrm{QT}, \mathrm{T}_{\mathrm{e}}$ mean, and $\mathrm{T}_{\mathrm{e}}$ variance $(P<0.05)$ compared to younger participants.
Compared to sham tDCS, anodal tDCS yielded RR, hemodynamic and repolarization variables changes in the older group only. In detail, $\mathrm{QT}_{\mathrm{e}} \mathrm{VI}, \mathrm{LF}_{\mathrm{RR}}, \mathrm{LF} / \mathrm{HF}$, and peripheral resistances decreased, whereas $\mathrm{QT}_{\mathrm{e}}$ mean, $\mathrm{T}_{\mathrm{e}}$ mean, $\mathrm{HF}_{\mathrm{RR}}$, and $\alpha \mathrm{HF}$ increased. In the younger group, peripheral resistances were significantly lower during active compared to sham tDCS.

Results from the stepwise multiple regression analysis detected a significant positive association between age and $\mathrm{QT}_{\mathrm{e}}$ VI (Figure 6), QT $\mathrm{p}$, and $\mathrm{T}_{\mathrm{e}}$ VI with similar regression coefficient and significance.

Table I Characteristics of the healthy elderly volunteers who underwent transcranial direct current stimulation

\begin{tabular}{llll}
\hline Characteristics & $\begin{array}{l}\text { Age } \\
<\mathbf{6 0} \text { years }\end{array}$ & $\begin{array}{l}\text { Age } \\
\geq \mathbf{6 0} \text { years }\end{array}$ & P-values \\
\hline Patients, $\mathrm{n}$ & 29 & 21 & \\
Men/women & $12 / 17$ & $1 \mathrm{I} / 10$ & $\mathrm{~ns}$ \\
Age, years & $36 \pm \mathrm{II}$ & $70 \pm 6$ & $<0.000 \mathrm{I}$ \\
Body mass index, $\mathrm{kg} / \mathrm{m}^{2}$ & $24 \pm 3$ & $25 \pm 3$ & $\mathrm{~ns}$ \\
Heart rate, beats/min & $68 \pm 9$ & $66 \pm 7$ & $\mathrm{~ns}$ \\
Systolic blood pressure, $\mathrm{mmHg}$ & $110 \pm 17$ & $108 \pm 7$ & $\mathrm{~ns}$ \\
Diastolic blood pressure, $\mathrm{mmHg}$ & $60 \pm 10$ & $61 \pm 10$ & $\mathrm{~ns}$ \\
\hline
\end{tabular}

Note: Data presented as mean \pm standard deviation unless stated otherwise. Abbreviation: ns, nonsignificant. 
Table $2 \mathrm{RR}, \mathrm{QT}_{\mathrm{e}}, \mathrm{QT}_{\mathrm{p}}$, and $\mathrm{T}_{\mathrm{e}}$ interval data in the healthy elderly volunteers who underwent sham and active tDCS

\begin{tabular}{|c|c|c|c|}
\hline Variables & $\begin{array}{l}\text { Age } \\
<60 \text { years }\end{array}$ & $\begin{array}{l}\text { Age } \\
\geq 60 \text { years }\end{array}$ & $P$-values \\
\hline \multicolumn{4}{|l|}{ Sham tDCS } \\
\hline Patients, $\mathrm{n}$ & 29 & 21 & \\
\hline $\mathrm{RR}$ mean, ms & $903 \pm 126$ & $914 \pm 106$ & ns \\
\hline $\mathrm{RR}$ variance, $\mathrm{ms}^{2}$ & $\mathrm{I}, 552(\mathrm{I}, 74 \mathrm{I})$ & $637(1,050)$ & 0.014 \\
\hline $\mathrm{QT}_{\mathrm{e}}$ mean & $334 \pm 24$ & $346 \pm 24 *$ & ns \\
\hline $\mathrm{QT}_{\mathrm{e}}$ variance, $\mathrm{ms}^{2}$ & $6(6)$ & $14(17)$ & 0.020 \\
\hline $\mathrm{QT}_{\mathrm{p}}$ mean & $260 \pm 22$ & $267 \pm 23$ & ns \\
\hline $\mathrm{QT}_{\mathrm{p}}$ variance, $\mathrm{ms}^{2}$ & $16(13)$ & $25(2 \mathrm{I})$ & ns \\
\hline$T_{e}$ mean & $75 \pm 11$ & $79 \pm 12^{2}$ & ns \\
\hline $\mathrm{T}_{\mathrm{e}}$ variance, $\mathrm{ms}^{2}$ & $21(20)$ & $36(34)$ & ns \\
\hline $\mathrm{QT}_{\mathrm{e}} \rightarrow \mathrm{RR}$, coherence & $0.205 \pm 0.030$ & $0.202 \pm 0.033$ & ns \\
\hline $\mathrm{QT}_{\mathrm{p}} \rightarrow \mathrm{RR}$, coherence & $0.223 \pm 0.044$ & $0.212 \pm 0.032$ & ns \\
\hline $\mathrm{T}_{\mathrm{e}} \rightarrow \mathrm{RR}$, coherence & $0.206 \pm 0.035$ & $0.205 \pm 0.029$ & ns \\
\hline $\mathrm{T}_{\mathrm{e}} \rightarrow \mathrm{QT}$, coherence & $0.683 \pm 0.199$ & $0.663 \pm 0.134$ & ns \\
\hline $\mathrm{QT}_{\mathrm{e}} \mathrm{VI}$ & $-1.44(0.60)$ & $-0.86(1.15)^{*}$ & 0.004 \\
\hline $\mathrm{QT}_{\mathrm{p}} \mathrm{VI}$ & $-0.95(0.68)$ & $-0.57(0.85)$ & 0.007 \\
\hline $\mathrm{T}_{\mathrm{e}} \mathrm{VI}$ & $0.30(0.70)$ & $0.68(0.70)$ & 0.004 \\
\hline \multicolumn{4}{|l|}{ Anodal tDCS } \\
\hline Patients, $\mathrm{n}$ & 29 & 21 & \\
\hline RR mean, ms & $897 \pm 125$ & $930 \pm 130$ & ns \\
\hline $\mathrm{RR}$ variance, $\mathrm{ms}^{2}$ & $\mathrm{I}, 543(\mathrm{I}, 9 \mid 5)$ & $723(106)$ & 0.004 \\
\hline $\mathrm{QT}_{\mathrm{e}}$ mean & $334 \pm 28$ & $353 \pm 30 *$ & 0.032 \\
\hline $\mathrm{QT}_{\mathrm{e}}$ variance, $\mathrm{ms}^{2}$ & $7(6)$ & $12(17)$ & 0.033 \\
\hline $\mathrm{QT}_{\mathrm{p}}^{\mathrm{e}}$ mean & $256 \pm 24$ & $266 \pm 28$ & ns \\
\hline $\mathrm{QT}_{\mathrm{p}}^{\mathrm{p}}$ variance, $\mathrm{ms}^{2}$ & $16(23)$ & $23(2 \mathrm{I})$ & ns \\
\hline $\mathrm{T}_{\mathrm{e}}$ mean & $78 \pm 10$ & $84 \pm 11 *$ & 0.030 \\
\hline $\mathrm{T}_{\mathrm{e}}$ variance, $\mathrm{ms}^{2}$ & $22(24)$ & $35(27)$ & 0.033 \\
\hline $\mathrm{QT}_{\mathrm{e}}^{\mathrm{e}} \rightarrow \mathrm{RR}$, coherence & $0.213 \pm 0.37$ & $0.204 \pm 0.32$ & ns \\
\hline $\mathrm{QT}_{\mathrm{P}} \rightarrow \mathrm{RR}$, coherence & $0.223 \pm 0.04 I$ & $0.211 \pm 0.043$ & ns \\
\hline $\mathrm{T}_{\mathrm{e}} \rightarrow \mathrm{RR}$, coherence & $0.205 \pm 0.027$ & $0.202 \pm 0.025$ & ns \\
\hline $\mathrm{T}_{\mathrm{e}} \rightarrow \mathrm{QT}_{\mathrm{p}}$, coherence & $0.726 \pm 0.148$ & $0.697 \pm 0.129$ & ns \\
\hline $\mathrm{QT}_{\mathrm{e}} \mathrm{VI}$ & $-1.70(0.60)$ & $-1.08(0.93)^{*}$ & 0.006 \\
\hline $\mathrm{QT}_{\mathrm{p}}^{\mathrm{e}} \mathrm{VI}$ & $-1.05(0.58)$ & $-0.55(0.68)$ & 0.009 \\
\hline T VI & $0.14(0.45)$ & $0.69(0.62)$ & 0.003 \\
\hline
\end{tabular}

Notes: Values expressed as mean \pm SD or median (interquartile range 75 th percentile to 25 th percentile). ${ }^{* P}<0.05$ sham vs tDCS. QT ${ }_{\mathrm{e}}$, QT interval (from q to end of $T$ wave); $Q T_{p}, Q_{p}$ interval (from $q$ to peak of $T$ wave); $T_{e}, T_{e}$ interval (from peak to end of $T$ wave).

Abbreviations: $t D C S$, transcranial direct current stimulation; ns, nonsignificant; $\mathrm{SD}$, standard deviation.

\section{Discussion}

The major finding in this study is that in participants older than 60 years anodal tDCS on the left TC reduces QTVI, $\mathrm{LF}_{\mathrm{NU}}, \mathrm{LF} / \mathrm{HF}$, and systemic peripheral resistances and increases $\mathrm{HF}_{\mathrm{NU}}$ and $\alpha \mathrm{HF}$. Thus, it seems that such stimulation improves temporal myocardial dispersion, reduces sympathetic sinus control, and increases vagal and baroreflex activity in elderly subjects..$^{29,36}$

Present results are in agreement with a previous study, which, using the same stimulation protocol, showed an
Table 3 Power spectral analysis of RR and SBP data in the healthy elderly volunteers who underwent sham and active tDCS

\begin{tabular}{|c|c|c|c|}
\hline Variables & $\begin{array}{l}\text { Age } \\
<60 \text { years }\end{array}$ & $\begin{array}{l}\text { Age } \\
\geq 60 \text { years }\end{array}$ & $P$-values \\
\hline \multicolumn{4}{|l|}{ Sham tDCS } \\
\hline Patients, $\mathrm{n}$ & 29 & 21 & \\
\hline $\mathrm{LF}_{\mathrm{RR}}, \ln \mathrm{ms}^{2}$ & $6.02 \pm 0.89$ & $5.15 \pm 1.49$ & 0.014 \\
\hline $\mathrm{HF}_{\mathrm{RR}}$, In $\mathrm{ms}^{2}$ & $5.65 \pm 1.07$ & $4.32 \pm 1.43$ & 0.001 \\
\hline $\mathrm{LF}_{\mathrm{RR}}, \mathrm{nu}$ & $5 \mathrm{I}(22)$ & $63(25)^{*}$ & ns \\
\hline $\mathrm{HF}_{\mathrm{RR}}$, nu & $42(24)$ & $26(24)^{*}$ & ns \\
\hline $\mathrm{LF} / \mathrm{HF}_{\mathrm{RR}}$ & $1.15(1.65)$ & $2.6(3.47)^{*}$ & ns \\
\hline $\mathrm{LF}_{\mathrm{SBP}}, \mathrm{mmHg}^{2}$ & $6(10)$ & $9(17)$ & ns \\
\hline$\alpha \mathrm{LF}, \mathrm{mmHg} / \mathrm{ms}$ & $7(8)$ & $6(4)$ & 0.020 \\
\hline$\alpha \mathrm{HF}, \mathrm{mmHg} / \mathrm{ms}$ & II (8) & $6(5)^{*}$ & 0.002 \\
\hline $\mathrm{SBP}_{\text {finomer }}, \mathrm{mmHg}$ & $110 \pm 17$ & $108 \pm 28$ & ns \\
\hline $\mathrm{DBP}_{\text {finomer, }}, \mathrm{mmHg}$ & $52 \pm 14$ & $5 I \pm 15$ & ns \\
\hline Stroke volume, $\mathrm{mL}$ & $69 \pm 12$ & $52 \pm 14$ & 0.001 \\
\hline Cardiac output, L/m & $4.47 \pm 0.87$ & $3.45 \pm 1.06$ & 0.001 \\
\hline $\begin{array}{l}\text { Systemic peripheral } \\
\text { resistance, u }\end{array}$ & I,579 (740)* & $2,155(I,|8|)^{*}$ & 0.01 \\
\hline \multicolumn{4}{|l|}{ Anodal tDCS } \\
\hline Patients, $\mathrm{n}$ & 29 & 21 & \\
\hline $\mathrm{LF}_{\mathrm{RR}}, \mathrm{ms}^{2}$ & $6.25 \pm 0.91$ & $5.26 \pm 1.32$ & 0.003 \\
\hline $\mathrm{HF}_{\mathrm{RR}}, \mathrm{ms}^{2}$ & $5.64 \pm 1.13$ & $4.90 \pm I .7 I$ & ns \\
\hline $\mathrm{LF}_{\mathrm{RR}}, \mathrm{nu}$ & $59(23)$ & $52(24)^{*}$ & ns \\
\hline $\mathrm{HF}_{\mathrm{RR}}, \mathrm{nu}$ & $36(21)$ & $40(23)^{*}$ & ns \\
\hline $\mathrm{LF} / \mathrm{HF}_{\mathrm{RR}}$ & $1.67(2.18)$ & $1.23(1.70)^{*}$ & ns \\
\hline $\mathrm{LF}_{\mathrm{SBP}}, \mathrm{mmHg} \mathrm{g}^{2}$ & $6(5)$ & $7(6)$ & ns \\
\hline$\alpha \mathrm{LF}, \mathrm{mmHg} / \mathrm{ms}$ & $9(6)$ & $6(7)$ & 0.018 \\
\hline$\alpha \mathrm{HF}, \mathrm{mmHg} / \mathrm{ms}$ & $13(10)$ & $8(10)^{*}$ & ns \\
\hline $\mathrm{SBP}_{\text {finomer }}, \mathrm{mmHg}$ & $102 \pm 14$ & $92 \pm 28$ & ns \\
\hline $\mathrm{DBP}_{\text {finomer, }}, \mathrm{mmHg}$ & $45 \pm 14$ & $44 \pm 15$ & ns \\
\hline Stroke volume, $\mathrm{mL}$ & $72 \pm 14$ & $53 \pm 16$ & 0.001 \\
\hline Cardiac output, L/m & $4.67 \pm 0.97$ & $3.44 \pm 0.97$ & 0.001 \\
\hline $\begin{array}{l}\text { Systemic peripheral } \\
\text { resistance, u }\end{array}$ & I,296 (428)* & $\mathrm{I}, 600(\mathrm{I}, \mathrm{I} \mid \mathrm{I}) *$ & 0.038 \\
\hline
\end{tabular}

Notes: Values are expressed as mean $\pm S D$ or median (interquartile range 75 th percentile to 25 th percentile). $* P<0.05$ sham vs tDCS.

Abbreviations: SBP, systolic blood pressure; tDCS, transcranial direct current stimulation; LF, low frequency power; HF, high frequency power; ns, nonsignificant; $\mathrm{nu}$, normalized units; DBP, diastolic blood pressure; SD, standard deviation.

increased parasympathetic activity (log of HF) and reduced sympathetic activity (log LF and LF/HF) in athletes but not in untrained subjects. ${ }^{11}$ Okano et $\mathrm{al}^{12}$ have replicated these previous results, and both studies speculated about the effects of the stimulation on the ANS in terms of the effects on the IC. Several clinical and experimental observations underline the close link between ischemic lesions in the IC, ANS control, and changes in ventricular repolarization and sudden cardiac death. In particular, acute stroke in the right IC increases plasma norepinephrine, increases the corrected QT interval, and worsens cardiovascular outcome at 1 year after stroke. ${ }^{41}$ The right IC therefore seems to play a crucial role in sympathetic activation, ${ }^{42,43}$ in modifying ventricular 


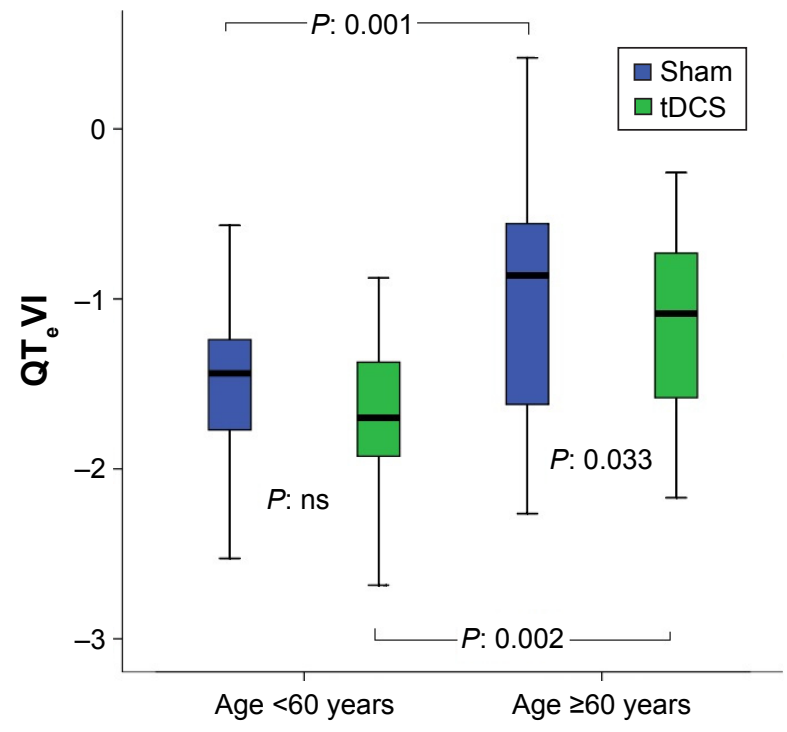

Figure $5 \mathrm{QT}_{\mathrm{e}} \mathrm{VI}$ during sham or anodal tDCS in volunteers younger and older than 60 years.

Notes: In the box plots, the central line represents the median distribution. Each box spans from 25 th to 75 th percentile points, and error bars extend from I0th to 90th percentile points.

Abbreviations: $\mathrm{QT}_{\mathrm{e}} \mathrm{VI}, \mathrm{QT}_{\mathrm{e}}$ variability index; tDCS, transcranial direct current stimulation; ns, nonsignificant.

repolarization, and in increasing sudden cardiac death risk. Indeed, sympathetic hyperactivity and increased temporal repolarization dispersion can induce malignant ventricular arrhythmias in patients with structural heart disease. ${ }^{22,39}$ No specific data are available on left insular stroke. Studies on left insular stroke ${ }^{44}$ report conflicting results presumably depending on the subjects' handedness. ${ }^{45}$

A limitation of our study is the relatively low spatial resolution of tDCS. ${ }^{46}$ Therefore, other brain regions besides the IC could also have been modulated. Since adjacent brain areas are also involved in ANS regulation, we cannot determine to which extent a possible adjacent modulation could have influenced the results. ${ }^{47}$
Limitation notwithstanding, a clinically relevant finding in our study is that anodal tDCS over T3 in healthy persons older than 60 years increases sinus parasympathetic activity and baroreflex sensitivity (increased $\mathrm{HF}_{\mathrm{NU}}$ and $\alpha \mathrm{HF}$ power). At the same as these variables change, sympathetic sinus activity diminishes (reduced $\mathrm{LF}_{\mathrm{NU}}$ and $\mathrm{LF} / \mathrm{HF}$ power) and so does temporal ventricular repolarization dispersion (reduced QTVI). This finding could have important clinical applications because it points to the use of tDCS as a potential tool to reduce hypertension in the elderly (via reducing systemic peripheral resistance) and, most important, to prevent malignant ventricular arrhythmias.

For confirming an age-related increase in $\mathrm{QT}_{\mathrm{e}} \mathrm{VI}$ (Figure 6), ${ }^{48}$ present data suggest that this index may improve during anodal tDCS in the elderly. Such improvement seems to depend mainly on the increased denominator, namely RR variance $(\sim 13 \%)$ given that concurrent $\mathrm{QT}_{\mathrm{e}}$ variance and QT mean increases worsen QT VI. Hence, rather than depending on a direct improvement in repolarization, $\mathrm{QT}_{\mathrm{e}} \mathrm{VI}$ seems to improve because of the increased heart rate variability, the exact change causing age-related QT VI worsening. The increased heart rate variability during tDCS undoubtedly depends on the increased sinus parasympathetic activity and simultaneous reduction in sympathetic activity, as the spectral data in our study confirm. Whatever mechanism is responsible for the reduced QT $\mathrm{VI}$, this marker's improvement clearly indicates a degree of clinical improvement in elderly. As well as being a marker of ventricular electrical instability, QT $\mathrm{VI}$ is also a clinical marker of hemodynamic compensation in the heart failure. ${ }^{22,26,34}$ Even though our data indicate that anodal tDCS may have improved $\mathrm{QT}_{\mathrm{e}} \mathrm{VI}$ and reduced peripheral resistance in healthy elderly subjects, no specific data on the elderly patients with heart failure with preserved left ventricular ejection fraction. ${ }^{49}$ It is well known that this syndrome,

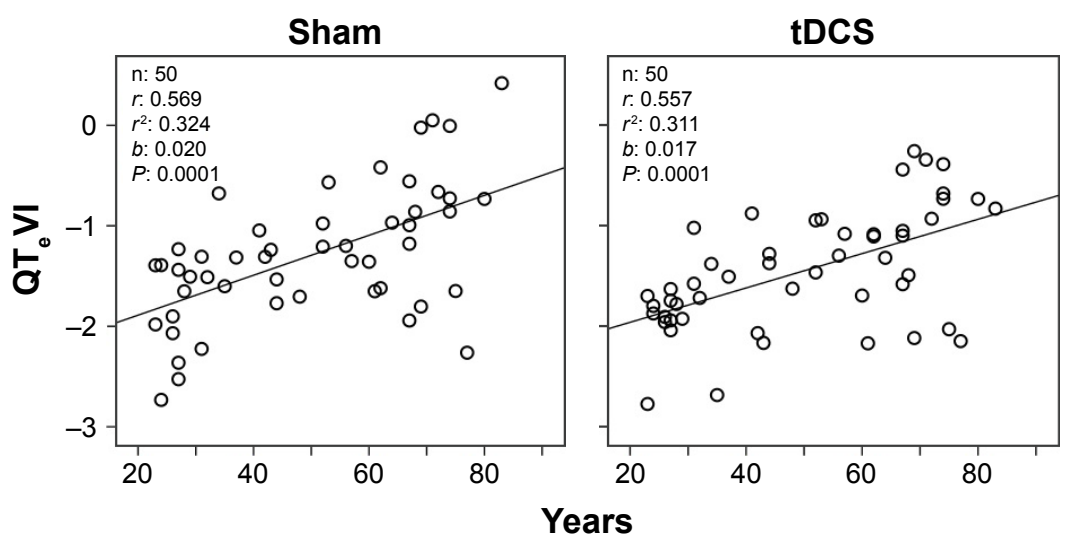

Figure 6 Relationship between $\mathrm{QT}_{\mathrm{e}}$ variability index $\left(\mathrm{QT}_{\mathrm{e}} \mathrm{VI}\right)$ and age in healthy control subjects during sham or active transcranial direct current stimulation (tDCS). 
extremely frequent in the elderly subjects, shows a clinical pattern characterized by normal ejection fraction, high peripheral resistance, and QT $\mathrm{VII}^{50,51}$ Moreover, chronic heart failure patients could improve their well known neuroautonomic impairment with this treatment. Therefore, the usefulness of these noninvasive brain stimulation methods as potential treatment for these populations needs to be established with randomized controlled trials. Another point to clarify is how to apply the stimulation: excluding a permanent, invasive stimulation, we could obtain some improvement by cyclic stimulation such as against depression and mania. Although the mechanism is unknown, neuronal plasticity could explain the neuronal lasting changes after brain stimulation. ${ }^{52}$

\section{Acknowledgments}

The Italian Ministry of Health Young Researcher Grant (GR-2011-02348232) awarded to Cristina Ottaviani has funded the study. The authors would like to thank Grazia Spitoni and Giorgio Pireddu for their valuable advice on the use of tDCS technique.

\section{Disclosure}

The authors report no conflicts of interest in this work.

\section{References}

1. Zipes DP, Wellens HJ. Sudden cardiac death. Circulation. 1998;98(21): 2334-2351.

2. Peacock J, Whang W. Psychological distress and arrhythmia: risk prediction and potential modifiers. Prog Cardiovasc Dis. 2013;55(6): 582-589.

3. Wicks AF, Lumley T, Lemaitre RN, et al. Major life events as potential triggers of sudden cardiac arrest. Epidemiology. 2012;23(3):482-485.

4. Taggart $P$, Critchley H, Lambiase PD. Heart-brain interactions in cardiac arrhythmia. Heart. 2011;97(9):698-708.

5. Katsanos AH, Korantzopoulos P, Tsivgoulis G, Kyritsis AP, Kosmidou M, Giannopoulos S. Electrocardiographic abnormalities and cardiac arrhythmias in structural brain lesions. Int J Cardiol. 2013;167(2): 328-334.

6. Koppikar S, Baranchuk A, Guzmán JC, Morillo CA. Stroke and ventricular arrhythmias. Int J Cardiol. 2013;168(2):653-659.

7. Nagai M, Hoshide S, Kario K. The insular cortex and cardiovascular system: a new insight into the brain-heart axis. J Am Soc Hypertens. 2010;4(4):174-182.

8. Sörös P, Hachinski V. Cardiovascular and neurological causes of sudden death after ischaemic stroke. Lancet Neurol. 2012;11(2):179-188.

9. Oppenheimer SM, Cechetto DF. Cardiac chronotropic organization of the rat insular cortex. Brain Res. 1990;533(1):66-72. What about Neurology 1992?.

10. Zhang ZH, Rashba S, Oppenheimer SM. Insular cortex lesions alter baroreceptor sensitivity in the urethane-anesthetized rat. Brain Res. 1998; 813(1):73-81.

11. Montenegro RA, FarinattiPde T, Fontes EB, et al. Transcranial direct current stimulation influences the cardiac autonomic nervous control. Neurosci Lett. 2011;497(1):32-36.

12. Okano AH, Fontes EB, Montenegro RA, et al. Brain stimulation modulates the autonomic nervous system, rating of perceived exertion and performance during maximal exercise. Br J Sports Med. 2015;49(18): 1213-1218.
13. Priori A, Berardelli A, Rona S, Accornero N, Manfredi M. Polarization of the human motor cortex through the scalp. Neuroreport. 1998; 9(10):2257-2260.

14. Piccirillo G, Di Giuseppe V, Nocco M, et al. Influence of aging and other cardiovascular risk factors on baroreflex sensitivity. J Am Geriatr Soc. 2001;49(8):1059-1065.

15. Piccirillo G, Fimognari FL, Munizzi MR, Bucca C, Cacciafesta M, Marigliano V. Age-dependent influence on heart rate variability in salt-sensitive hypertensive subjects. J Am Geriatr Soc. 1996;44(5): 530-538.

16. Piccirillo G, Fimognari FL, Viola E, Marigliano V. Age-adjusted normal confidence intervals for heart rate variability in healthy subjects during head-up tilt. Int J Cardiol. 1995;50(2):117-124.

17. Piccirillo G, Bucca C, Bauco C, et al. Power spectral analysis of heart rate in subjects over a hundred years old. Int J Cardiol. 1998;63(1): 53-61.

18. Colosimo A, Giuliani A, Mancini AM, Piccirillo G, Marigliano V. Estimating a cardiac age by means of heart rate variability. Am J Physiol. 1997;273(4 pt 2):H1841-H1847.

19. Giuliani A, Piccirillo G, Marigliano V, Colosimo A. A nonlinear explanation for aging induced changes in heart beat dynamics. Am J Physiol. 1998;275(4 pt 2):H1455-H1461.

20. Fisher JP, Kim A, Young CN, et al. Influence of ageing on carotid baroreflex peak response latency in humans. J Physiol. 2009;587(pt 22): 5427-5439.

21. Hotta H, Uchida S. Aging of the autonomic nervous system and possible improvements in autonomic activity using somatic afferent stimulation. Geriatr Gerontol Int. 2010;10(suppl 1):S127-S136.

22. Baumert M, Porta A, Vos MA, et al. QT interval variability in body surface ECG: measurement, physiological basis, and clinical value: position statement and consensus guidance endorsed by the European Heart Rhythm Association jointly with the ESC Working Group on Cardiac Cellular Electrophysiology. Europace. 2016;18(6):925-944.

23. Piccirillo G, Moscucci F, Persi A, et al. Intra-QT spectral coherence as a possible noninvasive marker of sustained ventricular tachycardia. Biomed Res Int. 2014;2014:583035.

24. Piccirillo G, Moscucci F, D’Alessandro G, et al. Myocardial repolarization dispersion and autonomic nerve activity in a canine experimental acute myocardial infarction model. Heart Rhythm. 2014;11(1): 110-118.

25. Piccirillo G, Moscucci F, Pascucci M, et al. Influence of aging and chronic heart failure on temporal dispersion of myocardial repolarization. Clin Interv Aging. 2013;8:293-300.

26. Piccirillo G, Rossi P, Mitra M, et al. Indexes of temporal myocardial repolarization dispersion and sudden cardiac death in heart failure: any difference? Ann Noninvasive Electrocardiol. 2013;18(2):130-139.

27. Piccirillo G, Magrì D, Pappadà MA, et al. Autonomic nerve activity and the short term variability of Tpeak-Tend interval in dogs with pacing pacing-induced heart failure. Heart Rhythm. 2012;9(12):2044-2050.

28. Monte-Silva K, Kuo MF, Liebetanz D, Paulus W, Nitsche MA. Shaping the optimal repetition interval for cathodal transcranial direct current stimulation (tDCS). J Neurophysiol. 2010;103(4):1735-1740.

29. Nitsche MA, Paulus W. Excitability changes induced in the human motor cortex by weak transcranial direct current stimulation. J Physiol. 2000;527(pt 3):633-639.

30. Frederiks J, Swenne CA, TenVoorde BJ, et al. The importance of highfrequency paced breathing in spectral baroreflex sensitivity assessment. J Hypertens. 2000;18(11):1635-1644.

31. Siebner HR, Lang N, Rizzo V, et al. Preconditioning of low-frequency repetitive transcranial magnetic stimulation with transcranial direct current stimulation: evidence for homeostatic plasticity in the human motor cortex. J Neurosci. 2004;24(13):3379-3385.

32. Boggio PS, Zaghi S, Lopes M, Fregni F. Modulatory effects of anodal transcranial direct current stimulation on perception and pain thresholds in healthy volunteers. Eur J Neurol. 2008;15(10):1124-1130.

33. Piccirillo G, Cacciafesta M, Viola E, et al. Influence of ageing on cardiac baroreflex sensitivity determined noninvasively by power spectral analysis. Clin Sci. 2001;100(3):267-274. 
34. Berger RD, Kasper EK, Baughman KL, Marban E, Calkins H, Tomaselli GF. Beat-to-beat QT interval variability: novel evidence for repolarization lability in ischemic and nonischemic dilated cardiomyopathy. Circulation. 1997;96(5):1557-1565.

35. Task Force of the European Society of Cardiology and the North American Society of Pacing and Electrophysiology. Heart rate variability: standards of measurement, physiological interpretation and clinical use. Circulation. 1996;93(5):1043-1065.

36. Robbe HWJ, Mulder LJM, Rüddel H, Langewitz WA, Veldman JBP, Mulder G. Assessment of baroreceptor reflex sensitivity by means of spectral analysis. Hypertension. 1987;10(5):538-543.

37. Pagani M, Somers V, Furlan R, et al. Changes in autonomic regulation induced by physical training in mild hypertension. Hypertension. 1988;12(6):600-610.

38. Piccirillo G, Luparini RL, Celli V, et al. Effects of carvedilol on heart rate and blood pressure variability in subjects with chronic heart failure. Am J Cardiol. 2000;86(12):1392-1395, A6.

39. Piccirillo G, Magrì D, Ogawa M, et al. Autonomic nervous system activity measured directly and QT interval variability in normal and pacing-induced tachycardia heart failure dogs. J Am Coll Cardiol. 2009;54(9):840-850.

40. Piccirillo G, Ogawa G, Song J, et al. Power spectral analysis of heart rate variability and autonomic nervous system activity measured directly in healthy dogs and dogs with tachycardia-induced heart failure. Heart Rhythm. 2009;6:546-552.

41. Sander D, Winbeck K, Klingelhöfer J, Etgen T, Conrad B. Prognostic relevance of pathological sympathetic activation after acute thromboembolic stroke. Neurology. 2001;57(5):833-838.

42. Colivicchi F, Bassi A, Santini M, Caltagirone C. Cardiac autonomic derangement and arrhythmias in right-sided stroke with insular involvement. Stroke. 2004;35(9):2094-2098.

43. Abboud H, Berroir S, Labreuche J, Orjuela K, Amarenco P, GENIC Investigators. Insular involvement in brain infarction increases risk for cardiac arrhythmia and death. Ann Neurol. 2006;59(4):691-699.
44. Laowattana S, Zeger SL, Lima JA, Goodman SN, Wittstein IS, Oppenheimer SM. Left insular stroke is associated with adverse cardiac outcome. Neurology. 2006;66(4):477-483.

45. Gonçalves EM, de Jesus SN. Stress prevention by modulation of autonomic nervous system (heart rate variability): a preliminary study using transcranial direct current stimulation. Open J Phychiathry. 2012;2: $113-122$.

46. Brunoni AR, Nitsche MA, Bolognini N, et al. Clinical research with transcranial direct current stimulation (tDCS): challenges and future directions. Brain Stimul. 2012;5(3):175-195.

47. Wager TD, Phan KL, Liberzon I, Taylor SF. Valence, gender, and lateralization of functional brain anatomy in emotion: a meta-analysis of findings from neuroimaging. Neuroimage. 2003;19:513-531.

48. Piccirillo G, Magnanti M, Matera S, et al. Age and QT variability index during free breathing, controlled breating and tilt in patient with chronic heart failure and healthy control subjects. Transl Res. 2006; 148(2):72-78.

49. Tereshchenko LG, Cygankiewicz I, McNitt S, et al. Predictive value of beat-to-beat QT variability index across the continuum of left ventricular dysfunction: competing risks of noncardiac or cardiovascular death and sudden or nonsudden cardiac death. Circ Arrhythm Electrophysiol. 2012;5(4):719-727.

50. Piccirillo G, Cacciafesta M, Lionetti M, et al. The influence of age, the autonomic nervous system and anxiety on QT interval variability. Clin Sci. 2001;101:429-438.

51. Piccirillo G, Moscucci F, D'Alessandro G. Temporal dispersion of ventricular repolarization phase and autonomic nervous system control: Clinical and experimental evidences. In: 2014 8th Conference of the European Study Group on Cardiovascular Oscillations, ESGCO 2014; Trento; Italy. 2014, Article number 6847559, Pages 141-142.

52. Schestatsky P, Simis M, Freeman R, Pascual-Leone A, Fregni F. Noninvasive brain stimulation and the autonomic nervous system. Clin Neurophysiol. 2013;124(9):1716-1728.
Clinical Interventions in Aging

\section{Publish your work in this journal}

Clinical Interventions in Aging is an international, peer-reviewed journal focusing on evidence-based reports on the value or lack thereof of treatments intended to prevent or delay the onset of maladaptive correlates of aging in human beings. This journal is indexed on PubMed Central, MedLine,

\section{Dovepress}

CAS, Scopus and the Elsevier Bibliographic databases. The manuscript management system is completely online and includes a very quick and fair peer-review system, which is all easy to use. Visit http://www.dovepress. com/testimonials.php to read real quotes from published authors. 